\title{
Special Issue in Honour of Anthony J (Tony) Turner
}

\author{
Natalia N. Nalivaeva ${ }^{1,2} \cdot$ John Hardy ${ }^{3}$
}

Published online: 19 March 2019

(c) Springer Science+Business Media, LLC, part of Springer Nature 2019

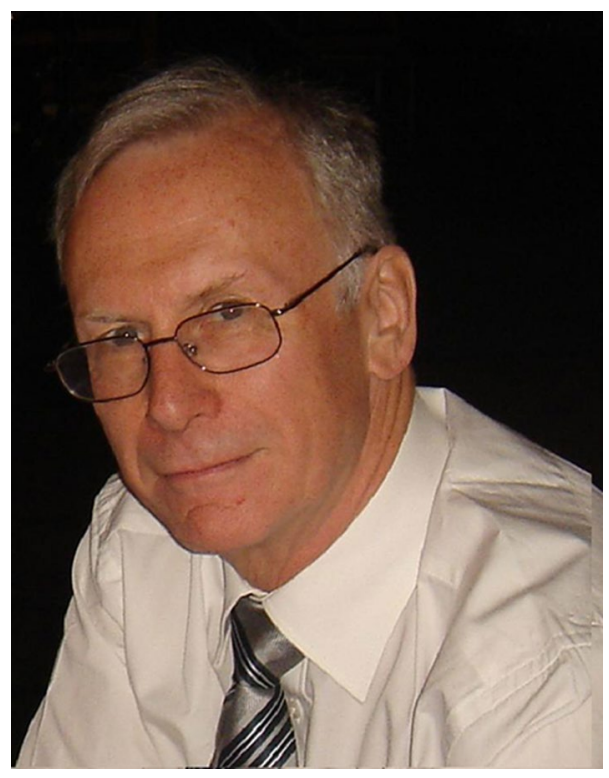

\section{Foreword}

With great pleasure we introduce this Special Issue of Neurochemical Research dedicated to Prof Anthony J (Tony) Turner whose research and administrative career over the years has been very tightly linked to neurochemistry.

Natalia N. Nalivaeva

n.n.nalivaeva@leeds.ac.uk

John Hardy

j.hardy@ucl.ac.uk

1 School of Biomedical Sciences, University of Leeds, Leeds LS2 9JT1, UK

2 I.M.Sechenov Institute of Evolutionary Physiology and Biochemistry, Saint Petersburg 194223, Russia

3 Department of Molecular Neuroscience, UCL Institute of Neurology, London, UK
Tony's research career began under the supervision of Prof Keith Tipton with whom, after graduating in 1969 from the University of Cambridge with a 1st Class degree in the Natural Sciences Tripos, he continued his postgraduate studies in the Department of Biochemistry at the University of Cambridge. He obtained his MA and then PhD degrees in 1973 and, with the award of a European Research Fellowship from the Royal Society, undertook post-doctoral research at the Mario Negri Institute of Pharmacology in Milan, Italy. On return to the UK in 1973 he was appointed as a Lecturer in Biochemistry at the University of Leeds where, over the years, he subsequently held the posts of Senior Lecturer, Reader in Neurochemistry and Professor of Biochemistry. In the period from 1996 to 2004 Tony was Head of the School of Biochemistry \& Molecular Biology and then, from 2004 to 2007, he was Dean of the Faculty of Biological Sciences at the University of Leeds. 
Tony has enjoyed a highly productive research career in which he has pioneered our understanding of the structure, function and biomedical applications of proteinases implicated in neurodegenerative and cardiovascular diseases, and in prostate cancer. In the 1980s he introduced the concept of the synaptic "neuropeptidase" and established the research area of membrane protein shedding by metalloproteinases. He was the first to identify and clone the angiotensin-converting enzyme-2 (ACE2) gene and its cardioprotective role has been a major pursuit in his research. His more recent work has shown the importance of lipid rafts and cholesterol in amyloid formation as well as of proteolytic enzymes, in particular of neprilysin, in amyloid clearance as therapeutic targets in Alzheimer's disease. More recently his research has also focused on the involvement of epigenetic mechanisms in neurodegeneration. Over the years Tony has supervised and guided the research work of $45 \mathrm{PhD}$ students and more than one hundred undergraduate research projects including that of one of the authors $(\mathrm{JH})$. His research has been presented in more than 250 research papers and he has also co-authored several text- and handbooks including contributing to several editions of the Handbook of Proteolytic Enzymes.

In addition to his scientific research, Tony has spent much of his effort in contributing to learned societies which has led to his close involvement in scientific publishing. He was Chief Editor of The Biochemical Journal (1987-1994) and of the Journal of Neurochemistry (1999-2010), Chair of Publications of the Biochemical Society and non-executive Chairman of its publishing arm, Portland Press (1994-2004). He was President of the European Society for Neurochemistry (1992-1996) and is currently Council member and Chair of Publications of the International Society for Neurochemistry (2011-2019) and Council member and Historian of the European Society for Neurochemistry (since 2013). In 2005 Tony was awarded the Distinguished Service Award by The Biochemical Society for his outstanding contributions to biochemistry.

Tony has a highly acclaimed international reputation and extensive collaborations with Universities and research institutions around the globe. He has been one of the facilitators and active participants of the Australian Peptide Association and of the Russian Society for Neurochemistry. He was a member of Programme and Advisory Boards of numerous specialist conferences in the UK and abroad. In 2003 he was awarded the degree of Honorary Doctor of Science and elected a member of the Scientific Council of the Institute of Evolutionary Physiology and Biochemistry of the Russian Academy of Sciences in St. Petersburg. For outstanding achievements in the field of neurochemistry and for promoting collaboration with the Jessenius Faculty of Medicine in Martin, Comenius University of Bratislava, Slovak Republic, on the occasion of the Faculty's 40th Anniversary in 2009, he was awarded the Dean's Gold Medal and in 2014 the degree of Doctor honoris causa by Comenius University in Bratislava (Slovakia). In 2012 he was elected as a Fellow of The Academy of Medical Sciences (UK) in recognition of his outstanding contribution to the advancement of medical science.

Tony is an enthusiastic traveller and keen photographer. He enjoys fine art, music, cricket and walking in the Yorkshire Dales. He enjoys meeting with his former PhD students and being updated on their progress both in science and in their personal lives.

This issue of Neurochemical Research has brought together scientists from various areas of neurochemistry around the world who, at various stages of their research career, have been working together with, or encouraged by, Tony's research. We are very pleased with the enthusiastic response to our invitation for contributing to this issue both with review and original research articles by all the authors, which give an outstanding overview of the state of the art in neurochemical research.

On behalf of all contributors, former $\mathrm{PhD}$ students and colleagues, as well as neurochemists from various regions of the globe we congratulate Tony with his outstanding scientific achievements and wish him to maintain this high level of involvement in science and neurochemistry for many years to come.

Natalia N. Nalivaeva and John Hardy Guest Editors

Publisher's Note Springer Nature remains neutral with regard to jurisdictional claims in published maps and institutional affiliations. 